Available online on 15.04.2020 at http://jddtonline.info
Open Access to Pharmaceutical and Medical Research
unrestricted non-commercial use, provided the original work is properly cited

Open@ Access

Research Article

\title{
How JRK's 777 oil demolishes the dense, viscous herbal rich oils can be ineffective for psoriasis
}

\author{
Aruna V*, Amruthavalli GV, Soundharya R, Gayathri R \\ Dr. JRK's Research and Pharmaceuticals Pvt. Ltd, No.18\& 19, Perumal Koil Street, Kunrathur, Chennai- 600069, India
}

\begin{abstract}
The present study deals with the importance of herbal particle size in the AYUSH oil preparations for psoriasis in order to achieve greater absorption and therapeutic value. More often the viscosity of the oil, deep colour and the density of herbal constituents are associated with superior therapeutic value. But our study has clearly demonstrated that the dermal absorbable herbal constituents (under $40 \mu \mathrm{m}$ ) was less than $10 \%$ in most of the Wrightia tinctoria based AYUSH oil preparations sold for the treatment of psoriasis in India whereas Dr. JRK's 777 oil contain more than $60 \%$ of the herbal constituents below $40 \mu \mathrm{m}$ size. Further the role of particle size besides dermal absorption; in the therapeutic value also established by oxygen species scavenging assay. Findings reveal that smaller the particles greater was the antioxidant effect and hence such herbal constituents not only would offer superior therapeutic effect but also protection to the oil from going rancid. Details are presented in the paper.
\end{abstract}

Keywords: AYUSH oils, Herbal oil, Psoriasis, dermal absorption, Wrightia tinctoria, rancid oil

Article Info: Received 06 Feb 2020; Review Completed 16 March 2020; Accepted 28 March 2020; Available online 15 April 2020

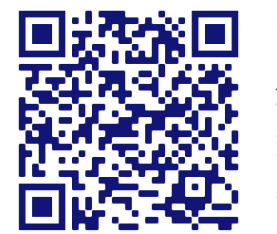

Cite this article as:

Aruna V, Amruthavalli GV, Soundharya R, Gayathri R, How JRK's 777 oil demolishes the dense, viscous herbal rich oils can be ineffective for psoriasis, Journal of Drug Delivery and Therapeutics. 2020; 10(2-s):105-114 http://dx.doi.org/10.22270/jddt.v10i2-s.3959

Aruna V, M.Pharm, Dr. JRK’s Research and Pharmaceuticals Pvt. Ltd, Chennai, India

\section{INTRODUCTION}

Dr. JRK's 777 oil is the first research based single herbal proprietary Siddha formulation invented and subsequently patented by CCRS under one of the first generation Siddha physicians and Padmasree awardee Dr. JR Krishnamoorthy, the founder of Dr. JRK's Research and Pharmaceuticals Pvt. Ltd. Chennai.1, 2, 3, 4

During his panoramic medical profession and several cross sectional interaction with the society Dr. Krishnamoorthy got the insight from a village is near Chengalpattu that the plant Wrightia tinctoria holds enormous therapeutic secret for the treatment of psoriasis. Subsequently Dr. Krishnamoorthy got himself associated with CCRAS, Chennai and then launched a nationwide research program on Wrightia tinctoria oil for Psoriais starting from laboratory experimentation, pre-clinical and safety evaluation and finally randomized, double blind clinical trial in patients and established undisputedly the therapeutic delight of Wrightia tinctoria for Psoriasis. 5, 6, 7, 8, 9

Further nuances were also studied and 777 oil formulation was thus arrived; which was later patented by CCRAS and patent right was conferred to NRDC, New Delhi.
Dr. Krishnamoorthy continued his research and established the 'probable group constituents' in Wrightia tinctoria that is responsible for the therapeutic effect, it's a rate of absorption through skin, the process required for the manufacturing of the same and thus Dr. JRK's 777 oil came into existence.

All over India the medical fraternity belongs to both allopathic and AYUSH have not only overwhelmingly accepted Dr. JRK's 777 oil but also accepted the exalted position of Dr. JRK's 777 oil in the treatment of psoriasis.

After seeing the success of Wrightia tinctoria in the treatment of Psoriasis, many Wrightia tinctoria based preparations have entered the market by exploiting the acceptance of Wrightia tinctoria, cost, colour, viscosity etc., as major 'cash point', doing the roost.

From the apparent examination, viscous and richly coloured oil is perceived as most effective drug than the oil which is quite thin and the herbal constituents in such preparation are near nano particle level.

Therefore many 'copycat' preparations are gaining importance in the market and simultaneously are affecting the reputation of Wrightia tinctoria under question because 
the patient dissatisfaction from many Wrightia tinctoria preparations are growing significantly.

The possible reason for the inferior therapeutic effect of many such Wrightia tinctoria preparations may be due to the obvious flaw and blemish in the manufacturing process and lack of understanding about the dermal absorption of herbal constituent's vis-à-vis the particle size.

In order to scientifically establish how Wrightia tinctoria preparation can be made effective and how the efficacy is linked with the particle size and also to prove how 'the appearance can be deceptive' in many such oil preparations, we have taken up an elaborate study on 'various subterranean' facets of Dr. JRK's 777 oil vis-à-vis various competitor brands in Indian and International market. The findings clearly warn the medical fraternity about how densely coloured, viscous oil can go least to no effect in treating psoriasis. Details are presented in the paper.

\section{MATERIALS AND METHODS}

\section{Details of the products studied}

\begin{tabular}{|c|c|}
\hline Details & Major ingredients \\
\hline Dr. JRK's 777 oil & Wrightia tinctoria \\
\hline Code A & Wrightia tinctoria, Hydnocarpus igdhiana \\
\hline Code B & Wrightia tinctoria \\
\hline Code C & Wrightia tinctoria \\
& Adathoda vasica \\
\hline Code D & Wrightia tinctoria \\
\hline Code E & Wrightia tinctoria \\
\hline Code F & Wrightia tinctoria \\
\hline
\end{tabular}

\section{Direct oil microscopy}

All the above oils were subjected to direct microscopy. In brief 20 microliter of the oil was placed over a microscope slide and then observed under $10 \mathrm{X}$ using a light microscope. The details such as herbal particle unevenness, size, distribution etc., and the respective images were photographed. The above experiment was done after through mixing of the oil.

\section{Size based herbal particle determination in different oil}

$30 \mathrm{ml}$ of oil was taken in a beaker and then $30 \mathrm{ml}$ of HPLC grade acetonitrile and methanol were added separately and the mixture was stirred for a while using magnetic stirrer. Then the solvent fraction was taken separately. OD value of the solvent fraction of different oils was read using spectrophotometer at $450 \mathrm{~nm}$. The respective solvent fractions of different oils were then filtered through sietz's filter with the following pore size such as 40,60, 100, $200 \mu \mathrm{m}$. The filtrates were then read through spectrophotometer at $450 \mathrm{~nm}$. The OD value of the solvent fraction of the respective oils before filtration served as control value. The OD value of the filtrate obtained through various pore sized filters was used to calculate the percentage of herbal particles present in the oil and their efficient dermal absorption.

The formula used for calculating the percentage of herbal constituents is as follow
OD value of control (before filtration)- OD value of the filtrate/OD value of control x 100

The above experiment was repeated after the respective oils were centrifuged at $1500 \mathrm{rpm}$ for 20 minutes.

Back test for confirmation of percentage presence of herbs present in oils by gradient filtration

The methanolic and acetonitrile fractions (centrifuged and un-centrifuged) of all the oils were read by spectrophotometer and the value thus obtained was taken as control. Subsequently the methanolic and acetonitrile fractions (centrifuged and un-centrifuged) were individually filtered by adopting gradient filtration method. In brief the methanolic fraction was first pass through $200 \mu \mathrm{m}$ filter, after reading the OD value of the filtrate, passed through $100 \mu \mathrm{m}$ filter and then through 60 and $40 \mu \mathrm{m}$ respectively and the respective OD values are also taken. From the OD value the percentage of herbal particle present with their particle size was calculated and was compared with the filtration done by non-gradient method.

\section{Determination of particle size versus therapeutic effect}

In order to understand the role of particle size of various herbal ingredients and the relative therapeutic value we have studied the free radical scavenging effect by studying the herbal fraction obtained with methanol.

\section{DPPH assay}

2,2 diphenyl-1-picrylhydrazyl (DPPH) is a dark-colored crystalline powder composed of stable free radical molecules. The DPPH assay method is based on the reduction in DPPH, a stable free radical. The free radical DPPH with an odd electron gives a maximum absorption at $517 \mathrm{~nm}$ (purple color). When antioxidants react with DPPH, which is a stable free radical becomes paired off in the presence of a hydrogen donor (e.g., a free radical scavenging antioxidant) and is reduced to the DPPHH and as consequence the absorbance decreases, the formation of DPPH to DPPHH results in decolorization (yellow color) with respect to the number of electrons captured. More the decolorization, more is the reducing ability of the test material. When a solution of DPPH is mixed with this substance that can donate a hydrogen atom, it gives rise to the reduced form of Diphenyl picryl hydrazine, a nonradical with the loss of violet color (although there would be a residual pale yellow color from the picryl group if present).

The absorbance of the samples was measured using UV 160 spectrophotometer at $517 \mathrm{~nm}$ against ethanol blank. A negative control was taken after adding DPPH solution to 0.2 $\mathrm{mL}$ of water. The percent of DPPH discoloration of the sample was calculated according to standard procedure. ${ }^{10}$

\section{Determination of particle size versus stability}

The extract of various plants used in different oils were prepared, filtered through sietz filter with different pore size, the respective filtrates were dried to evaporate the solvent and the extract thus obtained was incorporated separately into coconut oil. The prepared oils were stored in two distinct conditions, one being highly congenial for rancidity and other being dark, un-aerated, temperature controlled chamber to prevent rancidity. After 30 days of incubation, the oils were studied by kries test to determine the oxidative stress. The rate of oxidative stress of oil vis-àvis the particle size was scored as below,

$+++=$ highly rancid $\quad++=$ moderately rancid

$+=$ weakly rancid $\quad-=$ Nil 


\section{Kries test}

$1 \mathrm{ml}$ of the sample was mixed with $1 \mathrm{ml}$ of conc. Hydrochloric acid in a test tube. $1 \mathrm{ml} 1 \%$ solution of phloroglucinol prepared in diethyl ether was added to the above and then the mixture was mix thoroughly. The presence of a pink colour formation indicates the oxidized state of the oil while red colour denotes higher rate of oxidative stress.

\section{RESULTS}

Physical and chemical characteristics of Dr. JRK's 777 oil expressed in following table;

\begin{tabular}{|c|c|c|c|}
\hline \multirow{2}{*}{ Details } & \multicolumn{3}{|c|}{ Physical and chemical characteristics } \\
\cline { 2 - 4 } & Viscosity at 10rpm - S96 & Colour & Acid value \\
\hline Dr. JRK's 777 oil & 15,125 & Brilliant Pink & 1.15 \\
\hline Code A & 28,000 & Dark pink & 14.2 \\
\hline Code B & 27,300 & Dark pink & 22.5 \\
\hline Code C & 25,182 & Yellow colour & 16.9 \\
\hline Code D & 26,220 & Dark prown to pink & 24.9 \\
\hline Code E & 31,320 & Dark pink & 30.2 \\
\hline Code F & 29,700 & & 27.3 \\
\hline
\end{tabular}

\section{Direct oil microscopy}

On microscopic examination Dr. JRK's 777 oil showed very tiny sized herbal particles with almost even distribution. Further the physical appearance of the herbal particles were round or globule like - Image 1

Image 1- Dr. JRK's 777 oil

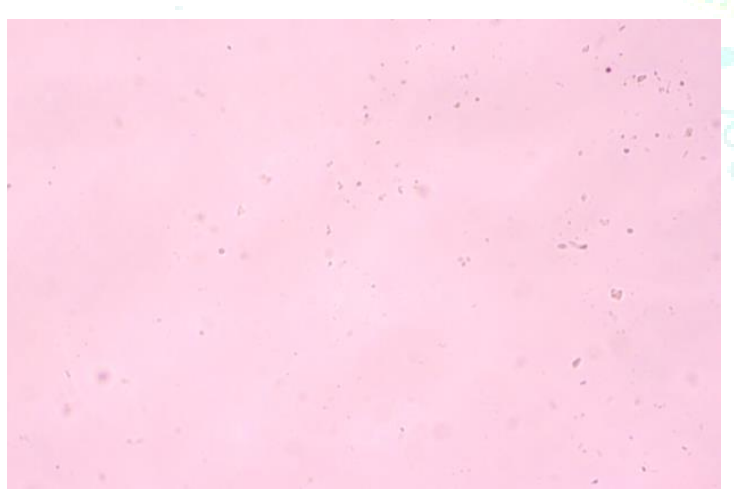

The microscopic examination of the oil sample -Code B revealed the presence of swam of emerging bees from its hive its appearance of herbal particles. Image 3

Image 3- Code B

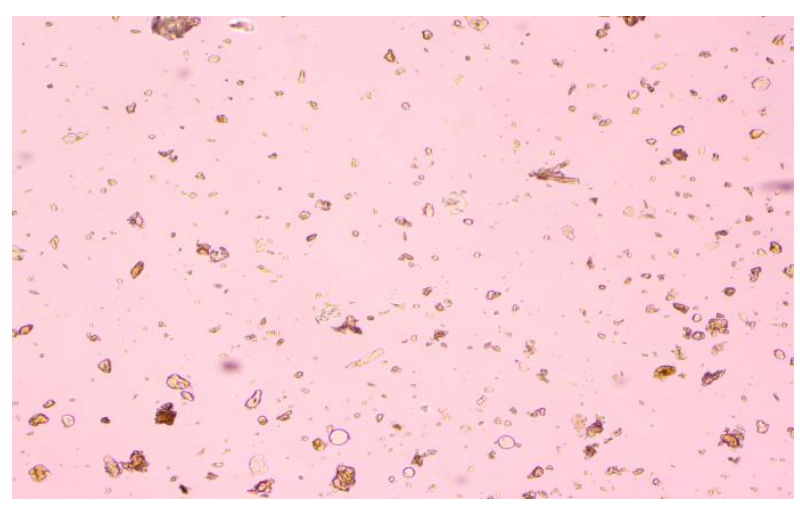

The competitor sample - code A on microscopic examination revealed that the herbal particles in the oil were quite irregular, indifferently shaped having spiky edges and clumps of grotesque agglomeration. Image 2

Image 2 - Code A



The microscopic examination of sample- Code $\mathrm{C}$ gives an appearance of tear shaped, evenly distributed herbal particles with regular clumps of differentially agglomerated herbal particles. Image 4

Image 4 - Code C




The microscopic examination of sample- Code D showed the presence of 'saw dust' distribution of herbal particles. Image 5. The microscopic examination of sample- Code E revealed half burned wood fiber appearance of the herbal particles. Image 6.

Image 5- Code E

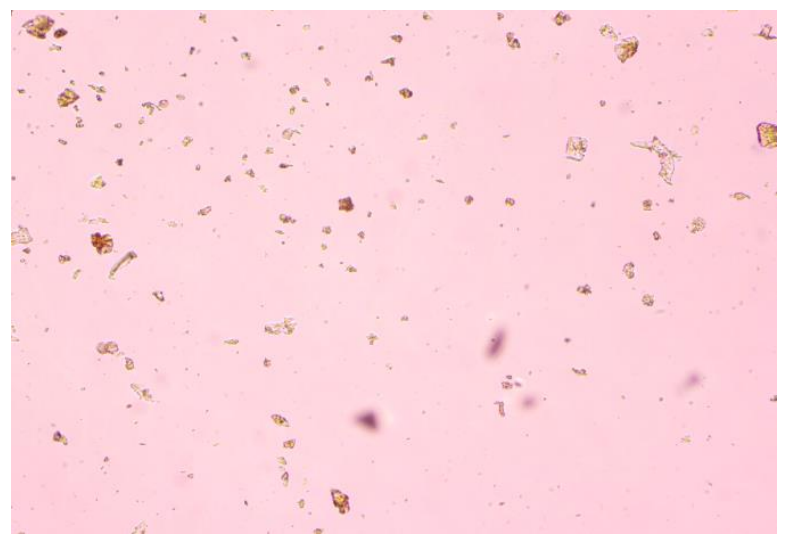

The microscopic examination of sample- Code F revealed the presence of 'blown out dust' appearance of the herbal particles. Image 7.

Image 7- Code F



\section{Size based herbal particle determination in different oil}

\section{Methanol fraction of oil}

The methanol fraction of Dr. JRK's 777 oil was filtered through 4 separate filters with different pore size. In Dr. JRK's 777 oil the herbal particles under $40 \mu \mathrm{m}$ was present at
Image 6- Code F

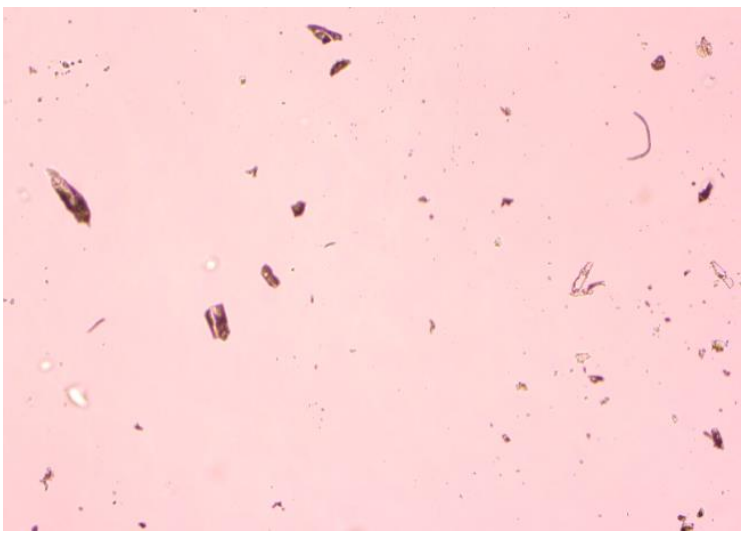

$52 \% .91 \%$ of the herbal particles in Dr. JRK's 777 oil were under $200 \mu \mathrm{m}$ size. Whereas the competitor samples starting from Code $\mathrm{A}$ to Code $\mathrm{F}$ showed the presence of herbal particle in the respective oils were less than $10 \%$ under particle size $40 \mu \mathrm{m}$. the herbal particle in all the competitor sample were only $25 \%$ below $200 \mu$ m. Table- 1 .

Table 1 Methanol fraction of oil

\begin{tabular}{|l|l|l|l|l|}
\hline \multirow{2}{*}{ Sample details } & \multicolumn{4}{|l|}{ \% of dissolved matter in the filtrate after filtration by Seitz's filter } \\
\cline { 2 - 5 } & $\mathbf{4 0 \mu \mathbf { m }}$ & $\mathbf{6 0} \boldsymbol{\mu m}$ & $\mathbf{1 0 0} \boldsymbol{\mu m}$ & $\mathbf{2 0 0} \boldsymbol{\mu m}$ \\
\hline JRK's 777 oil & 52 & 64 & 88 & 91 \\
Code A & 5 & 9 & 11 & 20 \\
Code B & 9 & 11 & 15 & 17 \\
Code C & 3 & 8 & 10 & 19 \\
Code D & 11 & 14 & 21 & 28 \\
Code E & 2 & 7 & 11 & 14 \\
Code F & 6 & 11 & 15 & 21 \\
\hline
\end{tabular}

The methanol fraction of Dr. JRK's 777 oil was centrifuged and then the filtrate was filtered through 4 separate filters with different pore size. In Dr. JRK's 777 oil the herbal particles under $40 \mu \mathrm{m}$ was present at $48 \% .98 \%$ of the herbal particles in Dr. JRK's 777 oil were under $200 \mu \mathrm{m}$ size. Whereas the competitor samples starting from Code A to
Code $\mathrm{F}$ showed the presence of herbal particle in the respective oils were less than $10 \%$ under particle size $40 \mu \mathrm{m}$. the herbal particle in all the competitor sample were only $15 \%$ below $200 \mu \mathrm{m}$. the centrifugation study has further revealed the highly soluble and dispersed state in Dr. JRK's 777 oil. Table- 2 . 
Table- 2 Methanol fraction of oil after oil being centrifuged at $1500 \mathrm{rpm}$ for 20 minutes

\begin{tabular}{|l|l|l|l|l|}
\hline \multirow{2}{*}{ Sample details } & \% of dissolved matter in the filtrate after filtration by Seitz's filter \\
\cline { 2 - 5 } & $\mathbf{4 0 \mu \mathbf { m }}$ & $\mathbf{6 0} \boldsymbol{\mu m}$ & $\mathbf{1 0 0} \boldsymbol{\mu m}$ & $\mathbf{2 0 0} \boldsymbol{\mu m}$ \\
\hline JRK's 777 oil & 48 & 76 & 90 & 98 \\
Code A & 3 & 4 & 7 & 9 \\
Code B & 2 & 6 & 11 & 13 \\
Code C & 1.8 & 3 & 8 & 11 \\
Code D & 5 & 2.9 & 14 & 16 \\
Code E & 3 & 5 & 7 & 11 \\
Code F & 3 & 7 & 11 & 14 \\
\hline
\end{tabular}

\section{Table 3}

The acetonitrile fraction of Dr. JRK's 777 oil was filtered through 4 separate filters with different pore size. In Dr. JRK's 777 oil the herbal particles under $40 \mu \mathrm{m}$ was present at $74 \% .88 \%$ of the herbal particles in Dr. JRK's 777 oil were under $200 \mu \mathrm{m}$ size. Whereas the competitor samples starting from Code $\mathrm{A}$ to Code $\mathrm{F}$ showed the presence of herbal particle in the respective oils were less than $10 \%$ under particle size $40 \mu \mathrm{m}$. the herbal particle in all the competitor sample were only $35 \%$ below $200 \mu \mathrm{m}$. Table- 3 .

Table- 3 Acetonitrile fraction of oil

\begin{tabular}{|l|l|l|l|l|}
\hline \multirow{2}{*}{ Sample details } & \multicolumn{4}{|l|}{ \% of dissolved matter in the filtrate after filtration by Seitz's filter } \\
\cline { 2 - 5 } & $\mathbf{4 0} \boldsymbol{\mu m}$ & $\mathbf{6 0} \boldsymbol{\mu m}$ & $\mathbf{1 0 0} \boldsymbol{\mu m}$ & $\mathbf{2 0 0} \boldsymbol{\mu m}$ \\
\hline JRK's 777 oil & 74 & 89 & 87 & 88 \\
Code A & 5 & 7 & 12 & 21 \\
Code B & 11 & 22 & 29 & 31 \\
Code C & 15 & 22 & 29 & 32 \\
Code D & 14 & 22 & 28 & 32 \\
Code E & 18 & 16 & 22 & 26 \\
Code F & 13 & 22 & 27 & 34 \\
\hline
\end{tabular}

The acetonitrile fraction of Dr. JRK's 777 oil was centrifuged and then the filtrate was filtered through 4 separate filters with different pore size. In Dr. JRK's 777 oil the herbal particles under $40 \mu \mathrm{m}$ was present at $72 \% .88 \%$ of the herbal particles in Dr. JRK's 777 oil were under $200 \mu \mathrm{m}$ size. Whereas the competitor samples starting from Code A to
Code $\mathrm{F}$ showed the presence of herbal particle in the respective oils were less than $10 \%$ under particle size $40 \mu \mathrm{m}$. the herbal particle in all the competitor sample were only $30 \%$ below $200 \mu \mathrm{m}$. the centrifugation study has further revealed the highly soluble and dispersed state in Dr. JRK's 777 oil. Table- 4 .

Table- 4 Acetonitrile fraction of oil after oil being centrifuged at $1500 \mathrm{rpm}$ for 20 minutes

\begin{tabular}{|l|l|l|l|l|}
\hline \multirow{2}{*}{ Sample details } & \% of dissolved matter in the filtrate after filtration by Seitz's filter \\
\cline { 2 - 5 } & $\mathbf{4 0} \boldsymbol{\mu m}$ & $\mathbf{6 0} \boldsymbol{\mu m}$ & $\mathbf{1 0 0} \boldsymbol{\mu m}$ & $\mathbf{2 0 0} \boldsymbol{\mu m}$ \\
\hline JRK's 777 oil & 72 & 80 & 89 & 88 \\
Code A & 11 & 14 & 17 & 22 \\
Code B & 7 & 9 & 13 & 29 \\
Code C & 9 & 13 & 19 & 24 \\
Code D & 13 & 15 & 22 & 28 \\
Code E & 8 & 13 & 22 & 30 \\
Code F & 8 & 11 & 20 & 29 \\
\hline
\end{tabular}

Back test for confirmation of percentage presence of herbs present in oils by gradient filtration

\section{Methanol fraction of oil}

The methanol fraction of Dr. JRK's 777 oil and the competitor samples were subjected to gradient filtration starting from 200 to $40 \mu \mathrm{m}$. The filtrates obtained from various pore size were used for determine the $\%$ of size based particle distribution. The gradient filtration method has reconfirmed that the herbal particles below $40 \mu \mathrm{m}$ is present in about 50\% in JRK's 777 oil whereas the status of other competitor products were far below 5\% Table- 5 . 
Table- $5 \%$ of dissolved matter in the filtrate after filtration by Seitz's filter

\begin{tabular}{|l|l|l|l|l|}
\hline \multirow{2}{*}{ Sample details } & \multicolumn{4}{|l|}{ \% of dissolved matter in the filtrate after filtration by Seitz's filter } \\
\cline { 2 - 5 } & $\mathbf{2 0 0} \boldsymbol{\mu m}$ & $\mathbf{1 0 0} \boldsymbol{\mu m}$ & $\mathbf{6 0} \boldsymbol{\mu m}$ & $\mathbf{4 0} \mathbf{m}$ \\
\hline JRK's 777 oil & 91 & 72 & 60 & 49 \\
Code A & 20 & 9 & 9 & 2 \\
Code B & 17 & 11 & 10 & 5 \\
Code C & 19 & 8 & 6 & 4 \\
Code D & 28 & 15 & 10 & 6 \\
Code E & 14 & 9 & 6 & 1 \\
Code F & 21 & 9 & 5 & 2 \\
\hline
\end{tabular}

The methanol fraction of Dr. JRK's 777 oil and the competitor samples were subjected to gradient filtration starting from 200 to $40 \mu \mathrm{m}$. The filtrates obtained from various pore size were used for determine the $\%$ of size based particle distribution. The gradient filtration method has reconfirmed that the herbal particles below $40 \mu \mathrm{m}$ is present in about $50 \%$ in JRK's 777 oil whereas the status of other competitor products were far below $1 \%$ Table- 6 .

Table- 6 Methanol fraction of oil after oil being centrifuged at $1500 \mathrm{rpm}$ for 20 minutes

\begin{tabular}{|l|l|l|l|l|}
\hline \multirow{2}{*}{ Sample details } & \% of dissolved matter in the filtrate after filtration by Seitz's filter & $\mathbf{4 0} \boldsymbol{\mu m}$ \\
\cline { 2 - 5 } & $\mathbf{2 0 0 \mu \mathbf { m }}$ & $\mathbf{1 0 0} \boldsymbol{\mu m}$ & $\mathbf{6 0} \mathbf{m}$ & 52 \\
\hline JRK's 777 oil & 98 & 87 & 2 & 1 \\
Code A & 9 & 5 & 3 & 1 \\
Code B & 13 & 7 & 1 & 1 \\
Code C & 11 & 5 & 1 & 1 \\
Code D & 16 & 11 & 2 & 1 \\
Code E & 11 & 4 & 3 & 1 \\
Code F & 14 & 9 & & \\
\hline
\end{tabular}

The acetonitrile fraction of Dr. JRK's 777 oil and the competitor samples were subjected to gradient filtration starting from 200 to $40 \mu \mathrm{m}$. The filtrates obtained from various pore size were used for determine the $\%$ of size based particle distribution. The gradient filtration method has reconfirmed that the herbal particles below $40 \mu \mathrm{m}$ is present in about 50\% in JRK's 777 oil whereas the status of other competitor products were far below $10 \%$ Table- 7.

Table- 7 Acetonitrile fraction of oil

\begin{tabular}{|l|l|l|l|l|}
\hline \multirow{2}{*}{ Sample details } & \multicolumn{4}{|l|}{ \% of dissolved matter in the filtrate after filtration by Seitz's filter } \\
\cline { 2 - 5 } & $\mathbf{2 0 0 \mu \mathbf { m }}$ & $\mathbf{1 0 0} \boldsymbol{\mu m}$ & $\mathbf{6 0} \mathbf{m m}$ & $\mathbf{4 0} \boldsymbol{\mu m}$ \\
\hline JRK's 777 oil & 88 & 78 & 72 & 64 \\
Code A & 21 & 9 & 4 & 1 \\
Code B & 31 & 20 & 11 & 6 \\
Code C & 32 & 19 & 10 & 9 \\
Code D & 32 & 18 & 11 & 8 \\
Code E & 26 & 10 & 9 & 7 \\
Code F & 34 & 17 & 15 & 9 \\
\hline
\end{tabular}

The acetonitrile fraction of Dr. JRK's 777 oil and the competitor samples were subjected to gradient filtration starting from 200 to $40 \mu \mathrm{m}$. The filtrates obtained from various pore size were used for determine the $\%$ of size based particle distribution. The gradient filtration method has reconfirmed that the herbal particles below $40 \mu \mathrm{m}$ is present in about $50 \%$ in JRK's 777 oil whereas the status of other competitor products were far below 10\% Table- 8 .

Table- 8 Acetonitrile fraction of oil after oil being centrifuged at $1500 \mathrm{rpm}$ for 20 minutes

\begin{tabular}{|l|l|l|l|l|}
\hline Sample details & \% of dissolved matter in the filtrate after filtration by Seitz's filter \\
\cline { 2 - 5 } & $\mathbf{2 0 0} \boldsymbol{\mu m}$ & $\mathbf{1 0 0} \boldsymbol{\mu m}$ & $\mathbf{6 0} \mathbf{m}$ & $\mathbf{4 0} \mathbf{\mu m}$ \\
\hline JRK's 777 oil & 88 & 82 & 11 & 65 \\
Code A & 22 & 11 & 5 & 9 \\
Code B & 29 & 9 & 7 & 4 \\
Code C & 24 & 11 & 6 & 3 \\
Code D & 28 & 14 & 10 & 5 \\
Code E & 30 & 18 & 4 & 2 \\
Code F & 29 & & & 2 \\
\hline
\end{tabular}


The methanolic extract of Wrightia tinctoria, Psoralea corylifolia, Azadirachta indica, Tinospora cordifolia, Adathoda vasica, Terminalia chebula, Terminalia bellerica, Emblica officnalis, Vettiver zianoides, Curcuma longa, Pungamia pinnata, Piper nigrum were prepared and were then subjected to gradient filtration using the filter with following pore size such as 500, 300, 100, 50 $\mu \mathrm{m}$ respectively. All the herbs showed greater antioxidant activity at particle size below $50 \mu \mathrm{m}$ when compared to the respective particle size close to $500 \mu \mathrm{m}$. further the above finding show clear concordance between the concentrations starting from $1 \mathrm{mg} / \mathrm{ml}$ to $3 \mathrm{mg} / \mathrm{ml}$. Table- 9 .

Table- 9 Antioxidant effect of various plants vis-à-vis particle size

\begin{tabular}{|c|c|c|c|c|c|c|}
\hline \multirow[b]{2}{*}{ Plant } & \multirow[b]{2}{*}{$\begin{array}{l}\text { Conc. } \\
\mathrm{mg} / \mathrm{ml}\end{array}$} & \multicolumn{5}{|c|}{ \% inhibition } \\
\hline & & $\begin{array}{l}\mathrm{MeOH} \\
\text { extract }\end{array}$ & $\begin{array}{c}\text { MeOH extract } \\
(500 \mu \mathrm{m})\end{array}$ & $\begin{array}{c}\text { MeOH extract } \\
(300 \mu \mathrm{m})\end{array}$ & $\begin{array}{c}\text { MeOH extract } \\
(100 \mu \mathrm{m})\end{array}$ & $\begin{array}{c}\text { MeOH extract } \\
(50 \mu \mathrm{m})\end{array}$ \\
\hline \multirow{3}{*}{ Wrightia tinctoria } & 1 & 7 & 11 & 20 & 31 & 48 \\
\hline & 2 & 6 & 20 & 25 & 35 & 52 \\
\hline & 3 & 10 & 28 & 34 & 41 & 62 \\
\hline \multirow{3}{*}{ Psoralea corylifolia } & 1 & 3 & 5 & 11 & 15 & 18 \\
\hline & 2 & 12 & 18 & 22 & 24 & 26 \\
\hline & 3 & 3 & 7 & 11 & 16 & 15 \\
\hline \multirow{3}{*}{ Azadirachta indica } & 1 & 3 & 8 & 12 & 11 & 17 \\
\hline & 2 & 5 & 9 & 12 & 12 & 16 \\
\hline & 3 & 5 & 11 & 16 & 15 & 17 \\
\hline \multirow{3}{*}{ Tinospora cordifolia } & 1 & 12 & 18 & 30 & 36 & 40 \\
\hline & 2 & 14 & 22 & 32 & 39 & 52 \\
\hline & 3 & 18 & 26 & 38 & 40 & 57 \\
\hline \multirow{3}{*}{ Adathoda vasica } & 1 & 6 & 11 & 18 & 21 & 26 \\
\hline & 2 & 7 & 12 & 20 & 25 & 28 \\
\hline & 3 & 9 & 14 & 21 & 26 & 31 \\
\hline \multirow{3}{*}{ Terminalia chebula } & 1 & 11 & 24 & 32 & 38 & 40 \\
\hline & 2 & 13 & 29 & 34 & 40 & 44 \\
\hline & 3 & 18 & 32 & 38 & 41 & 47 \\
\hline \multirow{3}{*}{ Terminalia bellerica } & 1 & 7 & 11 & 17 & 22 & 28 \\
\hline & 2 & 9 & 15 & 21 & 29 & 33 \\
\hline & 3 & 12 & 19 & 27 & 31 & 38 \\
\hline \multirow{3}{*}{ Emblica officnalis } & 1 & 22 & 34 & 38 & 42 & 52 \\
\hline & 2 & 28 & 39 & 44 & 50 & 64 \\
\hline & 3 & 31 & 40 & 49 & 56 & 68 \\
\hline \multirow{3}{*}{ Vettiver zianoides } & 1 & 5 & 9 & 10 & 11 & 18 \\
\hline & 2 & 6 & 10 & 12 & 18 & 20 \\
\hline & 3 & 8 & 12 & 18 & 21 & 24 \\
\hline \multirow{3}{*}{ Curcuma longa } & 1 & 18 & 22 & 30 & 35 & 40 \\
\hline & 2 & 24 & 28 & 34 & 40 & 50 \\
\hline & 3 & 31 & 39 & 41 & 46 & 61 \\
\hline \multirow{3}{*}{ Pungamia pinnata } & 1 & 3 & 8 & 11 & 18 & 20 \\
\hline & 2 & 5 & 9 & 15 & 21 & 24 \\
\hline & 3 & 7 & 11 & 18 & 24 & 28 \\
\hline \multirow{3}{*}{ Piper nigrum } & 1 & 15 & 22 & 28 & 35 & 41 \\
\hline & 2 & 20 & 28 & 34 & 40 & 47 \\
\hline & 3 & 30 & 38 & 47 & 52 & 60 \\
\hline
\end{tabular}

In order to understand the relationship between particle size versus antioxidant effect versus stability of the base oil the methanolic extract of various plants were subjected to gradient filtration and then incorporated into coconut oil and thus for oils with different particle size of herbal extracts were made.

The oil formulations were stored in an ideal condition as well as subjected to oxidative stress and then the oxidative stress of the oil with the herbal constituents of various particle size were assayed by kries test.

The lowest particle size (below $50 \mu \mathrm{m}$ ) of all the herbs exhibited greater activity and thereby the oxidative stress of the oil formulation with the herbal particle below $50 \mu \mathrm{m}$ was the lowest when compared to the particle size of the respective herbs $500 \mu \mathrm{m}$. the same trend was also observed in oil stored at ideal condition. Table $10 \& 11$. 
Table- 10 Particle size of herb versus stability- samples stored in ideal environment free of any trigger for rancidity

\begin{tabular}{|c|c|c|c|c|c|}
\hline \multirow[t]{2}{*}{ Name } & \multirow[t]{2}{*}{ Reading time } & \multicolumn{4}{|c|}{ Oils with different particle size of herb/kries test score } \\
\hline & & $(500 \mu \mathrm{m})$ & $(300 \mu \mathrm{m})$ & $(100 \mu \mathrm{m})$ & $(50 \mu \mathrm{m})$ \\
\hline \multirow[t]{2}{*}{ Wrightia tinctoria } & Before & - & - & - & - \\
\hline & After 30D & ++ & + & - & - \\
\hline \multirow[t]{2}{*}{ Psoralea corylifolia } & Before & - & - & - & - \\
\hline & After 30D & + & ++ & ++ & - \\
\hline \multirow[t]{2}{*}{ Azadirachta indica } & Before & - & - & - & - \\
\hline & After 30D & ++ & + & + & - \\
\hline \multirow[t]{2}{*}{ Tinospora cordifolia } & Before & - & - & - & - \\
\hline & After 30D & ++ & + & + & - \\
\hline \multirow[t]{2}{*}{ Adathoda vasica } & Before & - & - & - & - \\
\hline & After 30D & ++ & ++ & ++ & - \\
\hline \multirow[t]{2}{*}{ Terminalia chebula } & Before & - & - & - & - \\
\hline & After 30D & + & + & - & - \\
\hline \multirow[t]{2}{*}{ Terminalia bellerica } & Before & - & - & - & - \\
\hline & After 30D & + & - & - & - \\
\hline \multirow[t]{2}{*}{ Emblica officnalis } & Before & - & - & - & - \\
\hline & After 30D & + & + & + & - \\
\hline \multirow[t]{2}{*}{ Vettiver zianoides } & Before & - & - & - & - \\
\hline & After 30D & ++ & ++ & ++ & - \\
\hline \multirow[t]{2}{*}{ Curcuma longa } & Before & - & - & - & - \\
\hline & After 30D & + & - & - & - \\
\hline \multirow[t]{2}{*}{ Pungamia pinnata } & Before & - & - & - & - \\
\hline & After 30D & +++ & +++ & ++ & - \\
\hline \multirow[t]{2}{*}{ Piper nigrum } & Before & - & - & - & - \\
\hline & After 30D & + & - & - & - \\
\hline
\end{tabular}

Table- 11 Particle size of herb versus stability- samples stored in in-congenial environment to induce rancidity

\begin{tabular}{|c|c|c|c|c|c|}
\hline \multirow[t]{2}{*}{ Name } & \multirow[t]{2}{*}{ Reading time } & \multicolumn{4}{|c|}{ Oils with different particle size of herb/kries test score } \\
\hline & & $(500 \mu \mathrm{m})$ & $(300 \mu \mathrm{m})$ & $(100 \mu \mathrm{m})$ & $(50 \mu \mathrm{m})$ \\
\hline \multirow[t]{2}{*}{ Wrightia tinctoria } & Before & - & - & - & - \\
\hline & After 30D & +++ & ++ & ++ & - \\
\hline \multirow[t]{2}{*}{ Psoralea corylifolia } & Before & - & - & - & - \\
\hline & After 30D & +++ & ++ & ++ & - \\
\hline \multirow[t]{2}{*}{ Azadirachta indica } & Before & - & - & - & - \\
\hline & After 30D & +++ & ++ & ++ & - \\
\hline \multirow{2}{*}{ Tinospora cordifolia } & Before & - & - & - & - \\
\hline & After 30D & ++ & ++ & ++ & - \\
\hline \multirow[t]{2}{*}{ Adathoda vasica } & Before & - & - & - & - \\
\hline & After 30D & +++ & ++ & ++ & - \\
\hline \multirow{2}{*}{ Terminalia chebula } & Before & - & - & - & - \\
\hline & After 30D & + & + & + & - \\
\hline \multirow[t]{2}{*}{ Terminalia bellerica } & Before & - & - & - & - \\
\hline & After 30D & +++ & ++ & ++ & - \\
\hline \multirow[t]{2}{*}{ Emblica officnalis } & Before & - & - & - & - \\
\hline & After 30D & + & + & + & - \\
\hline \multirow[t]{2}{*}{ Vettiver zianoides } & Before & - & - & - & - \\
\hline & After 30D & +++ & ++ & ++ & - \\
\hline \multirow[t]{2}{*}{ Curcuma longa } & Before & - & - & - & - \\
\hline & After 30D & ++ & + & + & - \\
\hline \multirow{2}{*}{ Pungamia pinnata } & Before & - & - & - & - \\
\hline & After 30D & +++ & ++ & ++ & - \\
\hline \multirow[t]{2}{*}{ Piper nigrum } & Before & - & - & - & - \\
\hline & After 30D & + & + & + & - \\
\hline
\end{tabular}




\section{DISCUSSION}

Our present study has undoubtedly established the importance of intense research and proper scientific understanding of the formulation engineering of various Ayush preparations for making very effective Ayush product for the treatment of psoriasis.

It is often misjudged and over rated that viscous, deeply coloured, herbal rich oil is more effective than the one which is less viscous, brilliantly coloured with even distribution of herbal constituents.

More than how much of the herbal constituents that can enter inside the skin from the oil, how much of the herbal constituents present in the oil only create the perception of therapeutic superiority of such product among some patients and Ayush practitioner.

Our study has clearly admonished how appearance can go deceptive and how the patient as well as the Ayush practitioner needs to be aware of the above. It has been scientifically established that any pharmaceutical agent below $40 \mu \mathrm{m}$ size alone can permeate easily into the skin. And anything above $50 \mu \mathrm{m}$ can at best only get deposited over the skin and the skin permeation for such constituents is poor and so is the associated therapeutic benefit. ${ }^{11}$

Our study has really shocked and stunned the conventional notion that thick deeply colored oil is more effective, and in fact has questioned the basic treatment value of many Ayush preparations that are available in the form of oil meeting the above criteria of viscosity and herbal dominance.

Most of the market products had herbal particles and about $90 \%$ of them were above $200 \mu \mathrm{m}$ size. Further most of the market products were also disproportionately viscous, densely coloured and where rich in herbal extracts.

From the physical and visual experience such products can induce greater traction than the oil that is less viscous, brilliantly coloured and the herbal constituents at near nano particle size. To reconcile the data that we obtained from the filtration assay that Dr. JRK's 777 oil has 50\% herbal constituents which were below $40 \mu \mathrm{m}$. We have employed gradient filtration method to reconcile the above finding.

The round shaped, smooth edged herbal particles in Dr. JRK's 777 oil may be the reason for its better absorption by skin. It's already established that the preparations with round shaped and smooth edges or globule like substances get absorbed better through the intracellular space of the epidermis than the substances that are square-ish or triangular and or having spiky wall.

The herbal particles in Dr. JRK's 777 oil were not only below $40 \mu \mathrm{m}$ size but also were ovoid and hence could permeate easily inside the skin. Whereas the size and shape of the herbal particles in all competitor products were above $200 \mu \mathrm{m}$ and were having grotesque shape which points towards the absolute possibility of their poor to no absorption through skin. Further the percentage of such herbal constituents in those oils below $40 \mu \mathrm{m}$ size was less than $10 \%$.

After establishing the particle size and their respective possible dermal absorption, we raised another fundamental question that whether the particle size of herbal constituents is also important for the therapeutic efficacy or it is important only for dermal absorption.

The antioxidant value of all the herbs when tested individually showed greater activity at $50 \mu \mathrm{m}$ level than $500 \mu \mathrm{m}$. We presume that when particle size is too low the reactivity may increase and hence the ability to participate in the chemical reaction and the subsequent chemical changes also may increase concomitantly. The above findings reiterate the fact that the particle size below $40 \mu \mathrm{m}$ is not only inevitable for greater dermal absorption but is equally important for the therapeutic benefit as well.

Interestingly all the herbs used in the competitor products showed similar pattern which was in line with our proof on the size of the herbal particle above $200 \mu \mathrm{m}$ in the competitor products sums up nothing but they are ineffective, an unavoidable burden over skin and is pernicious wastage of money.

Why the antioxidant activity of the herbal constituents below $50 \mu \mathrm{m}$ was high when compared to $500 \mu \mathrm{m}$ when we followed gradient filtration method. We presume due to affinity of similar herbal constituents the smaller particles may be getting adhered to larger particles and thus the herb behaved and exhibit its activity only from the extend of $500 \mu \mathrm{m}$ size and hence show weak activity.

The antioxidant effects of the herbal constituents are also equally important for the base oil from getting rancid (Stability). In order to understand the fact that whether the particle size of the herb is important also for offering protection to the oil from accelerated oxidative stress.

The herbal constituents below $50 \mu \mathrm{m}$ could offer greater protection to oil from oxidative stress than the herbal particles of $500 \mu \mathrm{m}$ size. This once again proves that the particle size is important for absorption, therapeutic and stability. Dr. JRK's 777 oil meets all the above essentialities to offer superior therapeutic benefit.

The acid value analysis of Dr. JRK's 777 oil and various competitor products clearly showed that the acid value of the competitor products were as high as 15 to 30 . Whereas the acid value of Dr. JRK's 777 oil was 1.15. ${ }^{4}$

We have already established that rancid oil base is harmful to psoriasis than anyway beneficial. Further the rancid oil can also affect the therapeutic benefit of the herbal constituents that we have already established through the free radical scavenging ability of various herbal extracts in oils with varying acid value. 5

Our study serves a scary warning to both the patients and Ayush practitioner about how judgmentally wrong they might go by gauging the colour and other physical aspects of the Ayush preparations for psoriasis that are available in the market.

Viscosity, deep colour and high amount of herbal constituents in the oil can be deceptive from the therapeutic per se. Therefore the Ayush clinicians have additional responsibility to tell the patients about the efficacy of Ayush drugs must be understood and trusted based on the scientific credence and research support provided by manufacturer than by the mere physical appearance of the given preparation.

The involvement of mind, thoughts and once initial trust and acceptance over a product based on its physical parameters can cloud once impartial ability to question and examine the efficacy of the product that they are using for treating psoriasis. When the above factor come with certain cash advantages and the popular acceptance of the herb(s) that was used in the formulation, it is quite possible that the treating Ayush practitioner and the patient both are likely to bury their inquisitiveness to know the uglier side of the product that they use. 
Dr. JRK's Research and Pharmaceuticals adjudicates all its formulations through intense and elaborate research, preclinical evaluation, and clinical evaluation and all necessary scientific aspects on the mechanism of action, pharmacokinetic details, absorption, physical and chemical characteristics etc.

\section{CONCLUSION}

The present study on Dr.JRK's 777 oil impartially vindicates the superiority, science, therapeutic advantage, formulation uniqueness, product stability and finally assured safety of Dr. JRK's 777 oil over many other competitor brands that harvest cash over faith and gullibility of patients.

Our study also reinforces the science of ancient Ayush wisdom and how it can be made acceptable if we employ scientific temperament and science discipline to preserve and promote ancient health wisdom.

Dr. JRK's 777 oil is the gift of Siddha system of medicine, comes with scientific proof, fulfills all pharmacokinetic tenets that are essential for the prognosis and hence the subjective and reductionist observation over the physical aspects of some inferior oil in the market should not be allowed to influence the perception of efficacy over such products. Dr. JRK's 777 oil is most trusted for psoriasis and would certainly reward the patient with the expected treatment success.

\section{REFERENCES}

1. Saraswathy A, Joy S, Susan T, and Krishnamurthy J. R, Comparative study of 777 oil by High Performance Thin Layer Chromatography, Bulletin of Medico- Ethno- botanical Research, 1999; 20 (1-4):92- 101
2. Krishnamurty JR, Kalaimani S, Valuchamy G, Clinical study of Vetpalai (Wrightia tinctoria Linn.) oil in the treatment of Kalanjaga padai (Psoriasis), Journal of Research in Ayurveda and Siddha, 1981; 2 (1):58-65

3. Krishamoorthy JR, A Simple herbal formulation serves as a solution to a global skin problem, Invention intelligence, NovDec 2000

4. Aruna V, Gayathri Rajagopal, Abdul Abbas, Evidence for the Superior Quality and Efficacy of Dr. JRK's 777 Oil, Research \& Reviews: A Journal of Drug Design \& Discovery, 2017; 19-21

5. Aruna V, Gayathri Rajagopal, Rancid Oil: The Hidden Villain of Psoriasis, Research and Reviews: Journal of Unani, Siddha and Homeopathy, STM Journals. 2015; 2(2):22-25

6. Madhumati S, Gayathri Rajagopal, Karthik, Narasimhan S, Ramasamy. Secret of Dr.JRK's 777 oil-Pharmacognostic and Cell culture Revelation, Journal of Unani, Siddha and Homeopathy. 2015; 1(3).

7. Manuel MF, Boopalraj JM, Gomathi N, Jeevan J, Dhanalakshmi UR, Pandurangan CN. Efficacy of Dr. JRK's 777 Oil (Wrightia tinctoria) in the treatment of Psoriasis. The Antiseptic. 2001; 94(3): pp 75-76p.

8. Amruthavalli GV, Aruna V, Gayathri R. Clinical trial of combination therapy for the efficacy, safety, tolerability and improvements in quality of life in patients with moderate to severe plaque psoriasis. Int I Clin Trials, 2018; 5(3):121-6.

9. Aruna Vadivel, Amruthavalli Gatla Venkata, Soundharya Ravi, Gayathri Rajagopal. Uniqueness of Dr. JRK's 777 oil and how rancidity distorts Wrightia tinctoria, International Journal of Research in Dermatology, 2019; 5(3):618-624

10. Aruna V, Amruthavalli GV, Gayathri R. Use of cosmetic products for treating certain diseases- Know the science, J Cosmetic Dermatol, 2018: 1-5.

11. Pembe Oltulu, Bilsev Ince, Naile Kokbudak, Sidika Findik, Fahriye Kilinc. Measurement of Epidermis, Dermis, and Total Skin Thicknesses from Six Different Body Regions with a new Ethical Histometric Technique, Turk J Plast Surg, 2018; 26:5661. 